\title{
XXXVII. On the manner in which cotton unites with colouring matter
}

\section{Walter Crum Esq.}

To cite this article: Walter Crum Esq. (1844) XXXVII. On the manner in which cotton unites with colouring matter, Philosophical Magazine Series 3, 24:159, 241-246, DOI: $10.1080 / 14786444408644849$

To link to this article: http://dx.doi.org/10.1080/14786444408644849

册 Published online: 30 Apr 2009.

Submit your article to this journal

Џ Article views: 3

Q View related articles $\asymp$ 
A N D JOURNAL OF SCIENCE.

\author{
[THIRD SERIES.]
}

$A P R I L$ 184.4.

XXXVII. On the Manner in which Cotton unites roith Colouring Matter. By WalTer Crum, Esq., Vice-President of the Philosophical Society of Glasgow*.

THE effect of porous bodies in producing combination and 1 decomposition, independently of chemical affinity, has of late years occupied considerable attention.

If we examine, says Prof. Mitscherlich, a piece of box-wood by the microscope, we find it composed of cells which have a diameter of about $\frac{1}{2} \frac{1}{400}$ th of an inch. Heated to redness, the form of these cells suffers no change, for the particles of which it is composed have no tendency to run together in fusion. $\boldsymbol{A}$ cubic inch of box-wood charcoal boiled for some time in water absorbed five-eighths of its volume of that liquid; from which, and other data, it was computed that the surface of its pores was 73 square feet.

Saussure observed that a cubic inch of box-wood charcoal absorbed 35 cubic inches of carbonic acid; and as the solid part of the charcoal formed three-eighths of its bulk, these 35 inches of gas must have been condensed into five-eighths of an inch, or 56 cubic inches into one, under the ordinary pressure of the atmosphere. But carbonic acid liquefies under a pressure of 36.7 atmospheres, and therefore with a power of condensation equal to 56 atmospheres, which the charcoal exerted in Saussure's experiment, at least one-third of the gas must have assumed the liquid state within its pores.

Every other porous body has the same property as charcoal. Raw silk, linen, thread, the dried woods of hazel and mulberry, though they condense but a small quantity of carbonic acid, take up from 70 to 100 times their bulk of ammoniacal gas;

* Read before the Philosophical Society of Glasgow, February 1, 1843; and communicated to this Journal by the Author.

Phil. Mag. S. 3. Vol. 24. No. 159. April 1844. 
and Saxon hydrophane, which is nearly pure silica, absorbs 64 times its bulk. The gases enter into no combination with the solid which absorbs them, for the air-pump alone destroys their union.

The manner in which gases are attracted to the surfaces of solid bodies is very much like that which these exert on substances dissolved in water. The charcoal of bones has been long employed to remove colouring matter from the brown solution of tartaric acid, from syrup in the refining of sugar, and from a variety of other liquids containing organic substances; and it is found that the colouring matter so attracted remains attached to the surface of the charcoal without effecting any change upon it. In this animal charconl the carbon is mixed with ten times its weight of phosphate of lime, and if that be washed away by an acid, the remaining charcoal has nearly twice the decolorating power of an equal weight of ivoryblack. Bussy, who has made the action of these charcoals the subject of particular investigation, informs us that if ivoryblack, after the extraction of its earth of bones by an acid, be calcined along with potash, and the potash be afterwards washed out; or if blood be at once calcined with carbonate of potash and washed, the remaining charcoal has the power of decolorating twenty times as much syrup as could be done by the original bone charcoal. Animal charcoal removes also lime from lime water, iodine from a solution of iodide of potassium, and metallic oxides from their solutions in ammonia and caustic potash.

A satisfactory explanation of these remarkable facts has yet to be sought for. Mitscherlich calls the force which produces them an action of contact, or attraction of surface; and he calculates, as we have seen, the extent of surface in proportion to the mass as the measure of the force which it exerts. On the other hand, Saussure, in his valuable paper on the absorption of gases, informs us that charcoal from box-wood, in the solid state, absorbs twice as much common air as when it is reduced to powder. Now the effect of pulverization is certainly not to diminish the extent of surface. Saussure accounts for it in another way, and his explanation seems to connect many of the facts. The condensation of gases in solid charcoal goes on, he conceives, in the narrow cells of which it is composed, and is analogous to the rise of liquids in capillary tubes. In both, he says, the power appears to be in the inverse ratio of the size of the interior diameters of the pores or tubes of the absorbing bodies. When we pulverize a body containing such cells, we widen, open and destroy them. Fir charcoal, whose cells are wide, absorbs $4 \frac{1}{2}$ times its bulk of 
common air, and box-wood charcoal with smaller pores takes $7 \frac{1}{2}$. Charcoal from cork, with a specific gravity of only 0.1 , absorbs no appreciable quantity.

It appears to me that many of the operations of dyeing depend upon this influence of the surface, or the capillary action described by Saussure.

The microscopic examination of the fibres of cotton by $\mathrm{Mr}$. Thornson of Clitheroe, and Mr. Bauer, shows them to consist of transparent glassy tubes, which when unripe are cylindrical, and in the mature state collapsed in the middle, from end to end, giving the appearance of a separate tube on each side of the flattened fibre.

In many of the operations of dyeing and calico-printing the mineral basis of the colour is applied to the cotton in a state of solution in a volatile acid. This solution is allowed to dry upon the cloth, and in a short time the salt is decomposed, just as it would be in similar circumstances without the intervention of cotton. During the decomposition of this salt its acid escapes, and the metallic oxide adheres to the fibre so firmly as to resist the action of water applied to it with some violence. In this way does acetate of alumine act, and nearly in the same manner acetate of iron. The action here can only be mechanical on the part of the cotton, and the adherence, as I shall endeavour to show, confined to the interior of the tubes of which wools consist. The metallic oxide permeates these tubes in a state of solution, and it is only when its salt is there decomposed and the oxide precipitated and reduced to an insoluble powder, that it is prevented from returning through the fine filter in which it is then inclosed.

When the piece of cotton, which in this view consists of bags lined inside with a metallic oxide, is subsequently dyed with madder or logwood, and becomes thereby red or black, the action is purely one of chemical attraction between the mineral in the cloth and the organic matter in the dye vessel, which together form the red or black compound that results; and there is no peculiarity of a chemical nature from the mineral constituent being previously connected with the cotton. The process of cleansing in boiling liquids and in the washwheel, to which cotton printed with the various mordants is subjected previous to being maddered, is to remove those portions of metallic oxide which have been left outside the fibres or got entangled between them, and fastened there more or less firmly by the mucilage employed to thicken the solution.

The view $I$ have now given is in some respects the old mechanical theory of dyeing held by Macquer, Hellot, and Le Pileur d'Apligny, before the time of Bergman. Although $\mathrm{R} 2$ 
unacquainted with the microscopic appearance of cotton, d'Apligny argued that as no vegetable substance in its growth can receive a juice without vessels proper for its circulation, so the fibres of cotton must be hollow within. And of wool, he says, the sides of the tubes must be sieves throughout their length, with an infinity of lateral pores. We may gather also that he conceived dyeing to consist, first, in removing a medullary substance contained in the pores of the wool, and afterwards depositing in them particles of a foreign colouring matter.

But Bergman, in his Treatise on Indigo, in 1776 upset all this, and attributed to cotton a power of elective attraction, by which all the phænomena of dyeing were referred to purely chemical principles. Macquer soon adopted the chemical theory, and it was keenly advanced by Berthollet, who succeeded Dufay, Hellot and Macquer in the administration of the arts connected with chemistry. Berthollet has been followed by all, so far as I know, who have since that time written on the subject, but nothing like evidence has ever been produced; and if we only consider that chemical attraction necessarily involves combination, atom to atom, and consequently disorganization of all vegetable structure; that cotton wool may be dyed without injury to its fibre, and that that fibre remains entire when, by chemical means, its colour has again been removed, we shall find that the union of cotton with its colouring must be accounted for otherwise than by chemical affinity. In particular processes, as we shall afterwards see, attraction is no doubt exerted; but it is an attraction connected with structure, and therefore more mechanical than chemical.

When we examine with a powerful microscope a fibre of cotton, dyed either with indigo, with oxide of iron, chromate of lead, or the common madder-red, the colour appears to be spread so uniformly over the whole fibre that we cannot decide whether the walls of the tube are dyed throughout, or that the colouring matter only lines their internal surface. But the microscope shows that the collapse which occurs in raw and bleached cotton is very considerably diminished in the dyed.

The greater number of specimens of Turkey-red which I have examined show the same uniformity of colour, but in others of them little oblong balls appear all along the inside of the tube, of the fine pink shade of that dye, while the tube itself is colourless. It is in stout cloth dyed in the piece that these rounded masses occur, and the observation has been confirmed by several of my friends who are practised in microscopic re- 
search. But $I$ shall resume these observations with a more perfect instrument, which I hope soon to possess.

We have moreover the powerful analogy of the arrangement of colouring matter in plants in support of this view of the case. "Cellular tissue," says Dr. Lindley in his Introduction to Botany, "generally consists of little bladders or vesicles of various figures adhering together in masses. It is transparent, and in most cases colourless; when it appears otherwise its colour is caused by matter contained within it."...... "The bladders of cellular tissue are destitute of all perforations, so far as we can see, although, as they have the power of filtering liquids with rapidity, it is certain that they must abound in invisible pores."......" The brilliant colours of vegetable matters, the white, blue, yellow, scarlet, and other hues of the corolla, and the green of the bark and leaves, is not owing to any difference in the colour of the cells, but to the colouring matter of different kinds which they contain. In the stem of the garden balsam a single cell is frequently red in the midst of others which are colourless. Examine the red bladder, and you will find it filled with a colouring matter of which the rest are destitute. The bright satiny appearance of many richly-coloured flowers depends upon the colourless quality of the tissue. Thus in Thysanotus fascicularis, the flowers of which are of a deep brilliant violet, with a remarkably satiny lustre, that appearance will be found to arise from each particular cell containing a single drop of coloured fluid, which gleams through the white shining membrane of the tissue and produces the flickering lustre that is perceived." Cotton is itself cellular tissue, and the ligneous basis of all the forms of these vessels has the same chemical constitution.

I have alluded to another class of processes in dyeing in which the action much more resembles chemical affinity. I mean that in which pure cotton by mere immersion in different liquids withdraws a variety of substances from then solution. The "indigo vat" is a transparent solution, of a brownish yellow colour, consisting of deoxidized indigo combined with lime, and containing seldom more than $\frac{1}{50}$ th of its weight of colouring matter. By merely dipping cotton in this liquid the indigo attaches itself to it in the yellow state, in quantity proportioned within certain limits to the length of the immersion; and all that is necessary then to render it blue is to expose it to the air. Here an inactive spongy substance exercises a power which overcomes chemical affinity, but the mixture, which is formed of cotton and indigo, possesses none of the characters of a chemical compound. We can only recognise in this action the same force, whatever that may be, which 
enables animal charcoal to decolorate similar liquids. Charcoal, as we have also seen, withdraws metallic oxides from their solution in alkalies. Cotton wool has the same power, and it is extensively used as a means of dyeing with the yellow and red chromates of lead. If lime in excess be added to sugar of lead dissolved in a considerable quantity of water, the lead which precipitates is redissolved in the lime water and forms a weak solution of plumbate of lime. If a piece of cotton be immersed in this solution it appropriates the lead, and when afterwards washed and dipped in a solution of chrome, the lead becomes chromate of lead.

The same force enables cotton to imbibe basic salts of iron and tin by immersion in certain solutions of these metals; and many other examples of what Berzelius calls a catalytic force, in decomposing weak combinations, will occur to those who are familiar with the art of dyeing.

It appeared to me interesting to compare the amount of surface exposed by cotton wool with that of the more minute divisions of charcoal. I am enabled to furnish the following calculation through the kindness of Professor Balfour, who has measured with great care the fibres of various qualities of wool. The fibre of New Orleans wool varies most commonly from $\frac{1}{1500}$ th to $\frac{1}{200}$ th of an inch in diameter. About forty of these fibres or tubes compose a thread of No. 38 yarn (thirty-eight hanks to the pound). Ordinary printing cloth has, in the bleached state, 493 lineal feet of fibre, or 10.6 square inches of external surface of fibre in a square inch, which weighs nearly one grain. It is easy to compress 210 folds of this cloth into the thickness of one inch. It has then a specific gravity of 0.8 . One cubic inch has $94 \cdot 163$ lineal feet of tube, and 16.8 feet of external surface; or, if we include the internal surface, there are upwards of 30 square feet of surface of fibre in one cubic inch of compressed calico. The charcoal of box-wood has, as we have seen, 73 square feet of surface to the inch, with a specific gravity of $0.6^{*}$.

XXXVIII. Outline of the Geological Structure of North Wales. By the Rev. A. SEDGwick, F.G.S.†

\&1. Introduction.

TTHE author here describes in considerable detail the geographical 1 limits of the country under notice. For the structure of the Isle of Anglesea he referis to a paper by Prof. Henslow, published in the

* For drawings of cotton and linen see Phil. Mag., Nov. 1834. (S. 3. vol. v. p. 355.)

+ From the Proceedings of the Geological Society, vol, iv. p. 212, having been read June 21, 1843 . 